\title{
Evaluation of three intervention strategies to reduce the transmission of Salmonella Typhimurium in pigs
}

\author{
L. De Ridder ${ }^{\mathrm{a}, *}$, D. Maes ${ }^{\mathrm{b}}$, J. Dewulf ${ }^{\mathrm{b}}$, F. Pasmans ${ }^{\text {c }}$, F. Boyen ${ }^{\mathrm{c}}$, F. Haesebrouck ${ }^{\mathrm{c}}$, E. Méroc ${ }^{\mathrm{a}}$, P. Butaye ${ }^{\mathrm{a}, \mathrm{c}}$, \\ Y. Van der Stede ${ }^{a, d}$ \\ ${ }^{a}$ CODA-CERVA-VAR, Groeselenberg 99, 1180 Ukkel, Belgium \\ ${ }^{\mathrm{b}}$ Department of Obstetrics, Reproduction and Herd health, Faculty of Veterinary Medicine, Ghent University, Salisburylaan 133,9820 Merelbeke, Belgium \\ ' Department of Pathology, Bacteriology and Avian diseases, Faculty of Veterinary Medicine, Ghent University, Salisburylaan 133, 9820 Merelbeke, Belgium \\ ${ }^{\mathrm{d}}$ Laboratory of Immunology, Faculty of Veterinary Medicine, Ghent University, Salisburylaan 133, 9820 Merelbeke, Belgium
}

\section{A R T I C L E I N F O}

Article history:

Accepted 21 March 2013

\section{Keywords:}

Salmonella Typhimurium

Pig

Intervention strategies

Isolation

ELISA

\begin{abstract}
A B S T R A C T
Despite current control measures, Salmonella in pigs remains a major public health concern. In this in vivo study, the effect of three intervention strategies on Salmonella Typhimurium transmission in pigs was evaluated. The first intervention was feed supplemented with coated calcium-butyrate (group A); the second comprised oral vaccination with a double-attenuated Salmonella Typhimurium strain (group B), and the third was acidification of drinking water with a mixture of organic acids (group C). After challenge at 8 weeks of age, animals were individually sampled for 6 weeks (blood once per week; faeces twice per week) and then were euthanased at 14 weeks of age. Post-mortem ileum, caecum, ileocaecal lymph nodes, and tonsils were sampled, along with ileal, caecal and rectal contents, and tested for the presence of Salmonella spp. Transmission was quantified by calculating an 'adjusted' reproduction ratio ' $R_{a}$ ' and its $95 \%$ confidence interval $(\mathrm{CI})$.

The proportion of pigs that excreted Salmonella spp. via the faeces was significantly higher in group $C$ (58\%, $P<0.0001)$ and the positive control group (41\%, $P=0.03)$, compared to group $B(15 \%)$, and the proportion in group $C$ was also significantly higher than in group $A(23 \%, P=0.01)$. Group $A$ had the lowest proportion of positive post-mortem samples (18\%), followed by group B (31\%), the positive control group (41\%) and group $C(64 \%)(P<0.03)$. The highest transmission was seen in the positive control group and group C $\left(R_{a}=+\infty\right.$ with $\left.95 \% \mathrm{CI}[1.88 ;+\infty]\right)$, followed by group $\mathrm{B}\left(R_{a}=2.61[1.21 ; 9.45]\right)$ and $\mathrm{A}\left(R_{a}=1.76\right.$ $[1.02 ; 9.01])$. The results of this study suggest that vaccination and supplementation of the feed with coated calcium-butyrate limited Salmonella transmission in pigs and might be useful control measures.
\end{abstract}

(c) 2013 Elsevier Ltd. All rights reserved.

\section{Introduction}

Salmonella infection in pigs is a major concern in the European Union (EU), ${ }^{1}$ and in the past 10 years contaminated pork has been the second most important source of human salmonellosis in many EU countries (Hauser et al., 2010). Infection or contamination can occur at many different levels of the pig production chain such as via the feed, at the primary production site, in the slaughterhouse, and during pork processing. Salmonella infection and/or contamination at the primary production site plays a key role in this chain, as positive associations have been demonstrated between within-herd Salmonella seroprevalence and carcass contamination (Sørensen et al., 2004; Baptista et al., 2010), and reducing pre-slaughter Salmonella

\footnotetext{
* Corresponding author. Tel.: +322 3790416.

E-mail address: lotte.deridder@ugent.be (L. De Ridder).

1 See: Regulation (EC) No. 2160/2003.
}

infections increases pork safety, i.e. fewer infected lymph nodes and intestinal contents (Hurd et al., 2002).

Unfortunately, controlling Salmonella infections in pig herds is difficult. The pathogen is common, persists in the environment, and infections with most serovars occur without any obvious symptoms (Davies et al., 2004; EFSA, 2008). Although hygiene and biosecurity on-farm are of paramount importance in decreasing Salmonella seroprevalence in slaughterhouses (Hotes et al., 2011), Salmonella-free housing cannot be obtained simply by cleaning and disinfection regimens at farm level (Mannion et al., 2007; McLaren et al., 2011). Hence, such regimens should be combined with other measures as part of an overall strategy to control Salmonella on-farm (Wales et al., 2009).

Several studies have evaluated the effect on Salmonella control of on-farm treatment of feed or water with acids (Letellier et al., 2000; van der Wolf et al., 2001; Lo Fo Wong et al., 2004; Canibe et al., 2005; Farzan et al., 2006; Creus et al., 2007; Poljak et al., 2008; De Busser et al., 2009; Taube et al., 2009; Tanaka et al., 
2010). The results varied greatly between studies, possibly because of the large differences in the acidification process and dosage used (O'Connor et al., 2008). Of the different acidification methods and products, the use of coated butyric acid appears promising, as it decreased Salmonella shedding significantly in several studies (Van Immerseel et al., 2005; Boyen et al., 2008b; Guilloteau et al., 2010).

Another possible method of on-farm control of Salmonella infections in pigs is vaccination. In most studies the use of Salmonella Typhimurium vaccines significantly decreased clinical signs and excretion of Salmonella (Springer et al., 2001; Roesler et al., 2004, 2006; Eddicks et al., 2009; Farzan and Friendship, 2010; Hotes et al., 2011; Hur et al., 2011). However, Denagamage et al. (2007) concluded in their review that the design and reporting deficiencies in many studies (e.g. little detail on population type, sample size, type of vaccine, dose and dosing regimens) meant that the association between vaccination and Salmonella reduction in finisher swine was promising, but not proven. Furthermore, currently available serological tests do not differentiate between commercial-vaccine-induced and infection-induced antibodies, so vaccine use may be compromised in countries where serology is used for Salmonella surveillance (e.g. Denmark, Germany, UK, Belgium; EFSA, 2011).

To our knowledge, the ability of such intervention measures to prevent the spread of Salmonella among pigs has not yet been investigated via transmission experiments. A great advantage of such experiments is that the reduction of both the infectivity and susceptibility of treated animals can be quantified, whereas traditional challenge studies only demonstrate the effect of reduced susceptibility (Springer et al., 2001; Roesler et al., 2004; Tanaka et al., 2010). The aim of the present study was to evaluate, through the estimation of an adjusted reproduction ratio, the influence of three different intervention strategies, namely, (1) feed with coated calcium-butyrate, (2) vaccination, and (3) acidified drinking water, on the transmission in pigs of Salmonella enterica subspecies enterica serovar Typhimurium - the most prevalent Salmonella serotype in pigs in Belgium and Europe (CODA-CERVA, 2010; EFSA, 2012).

\section{Materials and methods}

This experiment was approved by the ethical committee of the Scientific Institute of Public Health and the Veterinary and Agrochemical Research Centre IPHVAR (100412-02).

\section{Herd selection}

For the initial survey, pig herds in the national Salmonella monitoring programme were selected, based on consistently low sample-to-positive $(\mathrm{S} / \mathrm{P})$ ratios $(\mathrm{S} / \mathrm{P}<0.20)$ in three consecutive blood samples taken from grower-finishing pigs in the preceding year. These herds were then visited, bacteriological and serological samples were taken, and the supply farm was selected based on hygiene, management and sample results.

\section{Piglet selection}

In order to select Salmonella-negative piglets, six sows from each selected herd were chosen through a bacteriological and serological screening process, which was repeated three times. From each sow, three piglets were screened as well. Finally, the sows with the lowest $\mathrm{S} / \mathrm{P}$ ratios were selected to provide the experimental piglets. The average $\mathrm{S} / \mathrm{P}$ ratio for the sampled piglets (at the time of the third screening at the age of 8 days) was $0.07 \pm 0.10$ (standard deviation).

A total of 69 piglets from six different sows were selected, weaned at 19 days of age and then transported to the experimental animal facilities of CODA-CERVA in a thoroughly cleaned and disinfected trailer.

\section{Study design}

Upon arrival, the piglets were randomly assigned into five groups: Group A $(n=2 \times 8)$ received feed supplemented with $0.3 \% \mathrm{~m} / \mathrm{m}$ coated calcium-butyrate salt (Greencab-70, Sanluc International) (see Table 1 for details), group B $(n=2 \times 8)$ was orally vaccinated at 22 and 43 days of age with $5 \times 10^{8}-5 \times 10^{9}$ colony forming
Table 1

Composition of the feed (group A) and water (group C) supplement.

\begin{tabular}{lll}
\hline Ingredients & \% in supplement $\%$ in feed (1) or water (2) \\
\hline (1) Feed supplement in group A & & \\
Butyrate anion & \pm 70.0 & \pm 2.1 \\
Calcium (organic) & \pm 14.0 & \pm 0.4 \\
Free fatty acids & \pm 10.0 & \pm 0.3 \\
C16:0 & $7.5-9.0$ & $0.23-0.27$ \\
C18:0 & $0.5-1.0$ & $0.02-0.03$ \\
C18:1 & $0.5-1.0$ & $0.02-0.03$ \\
C14:0 & $<0.35$ & $<0.01$ \\
(2) Water supplement in group C & $(\mathrm{pH} 2.0-3.5)$ & $(\mathrm{pH} 3.6-4.0)$ \\
Formic acid & $>50$ & $>0.044$ \\
Propionic acid & $>10$ & $>0.009$ \\
Acetic acid & $>10$ & $>0.009$ \\
Lactic acid & $<5$ & $<0.004$ \\
\hline
\end{tabular}

Group A was given deodorized calcium-butyrate salt coated with plant oils in the pig meal, while group $C$ received a mixture of organic acids in the drinking water.

units (CFU) of a double-attenuated histidine-adenine auxotrophic Salmonella Typhimurium vaccine (Salmoporc, Impfstoffwerk Dessau-Tornau), and group C $(n=2 \times 8)$ received drinking water adjusted to $\mathrm{pH} 3.6-4.0$ using $0.09 \% \mathrm{v} / \mathrm{v}$ of a mixture of formic, propionic, acetic and lactic acid (Agrocid Super, CidLines) (see Table 1 for details). This water was checked daily with a pH-meter (pHep + ATC, Hanna Instruments). A positive control group (infected/untreated; $n=2 \times 8$ ) and a negative control group (uninfected/untreated; $n=5$ ) were also included. All treatments were applied from arrival in the experimental facilities ( 3 weeks of age) until the end of the experiment (14 weeks of age).

All animals were fed the same meal without antimicrobials throughout the study, except for group A where the feed was supplemented as described above. Every group was housed in a different room with two similar pens ( $2 \times 8$ pigs) which were separated with solid $1 \mathrm{~m}$ high partitions. The stocking density was $0.42 \mathrm{~m}^{2}$ per pig.

At 57 days of age, two pigs in each pen (except for those in the negative control group) were moved to a separate room and were orally challenged (Day -1 ) with $10^{8} \mathrm{CFU}$ of a nalidixic acid-resistant Salmonella Typhimurium strain $112910 \mathrm{a}$, previously isolated from a pig without clinical signs of salmonellosis by Boyen et al (2008a). Twenty-four hours after this challenge, these 'seeder' pigs were replaced into their original pens (Day 0). All pigs were euthanased and autopsied at 95 days of age (Day 37).

\section{Sampling}

The sampling scheme is shown in Table 2. From 3 weeks of age (Day -39) until euthanasia at 14 weeks of age (Day 37), blood samples were obtained from all 69 pigs once a week to detect Salmonella-specific antibodies via ELISA. From 3 weeks of age (Day -39) until challenge (Day -1) pooled faecal samples were taken weekly. After challenge, individual faecal samples were collected from all pigs twice a week. At autopsy (Day 37), samples of ileocaecal lymph nodes, ileum, ileal content, caecum, caecal content, faeces and tonsils were taken, and examined bacteriologically.

\section{Bacteriological examination}

Faecal examination was initiated within $2 \mathrm{~h}$ of collection. Salmonella was isolated using the ISO 6579 Annex D method (ISO 6579:2002). Briefly, samples were inoculated in buffered peptone water (BPW, Bio-Rad) in dilution 1:10 and incubated aerobically for $16-20 \mathrm{~h}$ at $37^{\circ} \mathrm{C}$. Of this solution, $0.1 \mathrm{~mL}$ was inoculated on a modified semi-solid Rappaport Vassiliadis plate (MSRV, Bio-Rad) and incubated aerobically at $42{ }^{\circ} \mathrm{C}$ for $48 \mathrm{~h}$. Growth halos were plated on a xylose lysine deoxycholate agar plate (XLD, Bio-Rad) and a brilliant green agar plate (BGA, LabM) - the latter supplemented with $20 \mu \mathrm{g} / \mathrm{mL}$ nalidixic acid - and then incubated aerobically for 21-27 h at $37^{\circ} \mathrm{C}$. One Salmonella-suspected colony on these XLD plates (challenge or vaccine strain) or on the BGA plates (only the challenge strain) was inoculated in triple sugar iron agar (TSI, Bio-Rad) and lysine decarboxylase bouillon (Oxoid) and incubated for $18-24 \mathrm{~h}$ at $37{ }^{\circ} \mathrm{C}$ for final identification.

For samples from group B, when growth of Salmonella bacteria was only observed on XLD and not on BGA, the sample was additionally tested with medium A and B (Salmonella Diagnostic Kit, IDT) to confirm that the isolated bacterium was the vaccine strain. Quantification of Salmonella spp. was performed on faecal samples 3, 7 and 24 days post infection (DPI) using standard enumeration protocols (Boyen et al., 2008a).

The tissue samples taken at necropsy were first rinsed with phosphate buffered saline, then sliced, suspended in BPW (dilution 1:10) and homogenized in a stomacher (BagMixer, Interscience) for $1 \mathrm{~min}$. Further isolation was performed as for the faecal samples. 
Table 2

Experimental design of the transmission study with the taken samples/actions and the used diagnostics/products, in function of the age of the pigs.

\begin{tabular}{|c|c|c|c|c|c|c|c|c|c|c|c|c|c|}
\hline \multirow[t]{2}{*}{ Sampling/action (frequency) } & \multicolumn{12}{|c|}{ Age of the pigs (weeks) } & \multirow[t]{2}{*}{ Diagnostic method/product } \\
\hline & 3 & 4 & 5 & 6 & 7 & 8 & 9 & 10 & 11 & 12 & 13 & 14 & \\
\hline Pooled faeces per pen (once/week) & $\mathrm{x}$ & $\mathrm{x}$ & $\mathrm{x}$ & $\mathrm{x}$ & $\mathrm{x}$ & $\mathrm{x}$ & & & & & & & Isolation $^{\mathrm{a}}$ \\
\hline Individual rectal faeces (twice/week) & & & & & & & $\mathrm{x}$ & $\mathrm{x}$ & $\mathrm{x}$ & $\mathrm{x}$ & $\mathrm{x}$ & $\mathrm{x}$ & Isolation $^{\mathrm{a}}$ \\
\hline Blood (once/week) & $\mathrm{x}$ & $\mathrm{x}$ & $\mathrm{x}$ & $\mathrm{x}$ & $\mathrm{x}$ & $\mathrm{x}$ & $\mathrm{x}$ & $\mathrm{x}$ & $\mathrm{x}$ & $\mathrm{x}$ & $\mathrm{x}$ & $\mathrm{x}$ & ELISA $^{\mathrm{b}}$ \\
\hline Supplementations in feed (A) and water (C) (ad libitum) & $\mathrm{x}$ & $\mathrm{x}$ & $\mathrm{x}$ & $\mathrm{x}$ & $\mathrm{x}$ & $\mathrm{x}$ & $\mathrm{x}$ & $\mathrm{x}$ & $\mathrm{x}$ & $\mathrm{x}$ & $\mathrm{x}$ & $\mathrm{x}$ & $\begin{array}{l}\text { Feed: coated calcium-butyrate salt (Greencab- } \\
\text { 70, Sanluc International) } \\
\text { Water: mixture of organic acids (Agrocid Super, } \\
\text { CidLines) }\end{array}$ \\
\hline Vaccination (B) (primer + boost) & $\mathrm{x}$ & & & $\mathrm{x}$ & & & & & & & & & $\begin{array}{l}\text { Commercial Salmonella Typhimurium vaccine } \\
\text { (Salmoporc, IDT) }\end{array}$ \\
\hline Challenge (two pigs/group) & & & & & & $\mathrm{x}$ & & & & & & & $\begin{array}{l}\text { Nalidixic acid resistant Salmonella } \\
\text { Typhimurium strain } 112910 a\end{array}$ \\
\hline $\begin{array}{l}\text { Rectal faeces, ileum + content, caecum + content, ileocaecal } \\
\text { lymph nodes, tonsils (autopsy) }\end{array}$ & & & & & & & & & & & & $\mathrm{x}$ & Isolation $^{\mathrm{a}}$ \\
\hline
\end{tabular}

a According ISO 6579 Annex D: http://eur-lex.europa.eu/LexUriServ/LexUriServ.do?uri=OJ:L:2011:314:0012:0013:NL:PDF.

b Commercial ELISA kit (HerdChek Swine Salmonella, IDEXX Laboratories).

\section{Serological examination}

Blood samples were allowed to clot for $24 \mathrm{~h}$ at $15^{\circ} \mathrm{C}$ and were then centrifuged for $15 \mathrm{~min}$ at $1200 \mathrm{~g}$. Serum was diluted 20-fold and analysed for Salmonella-specific antibodies with a commercial ELISA-kit based on lipopolysaccharide (LPS) antigens (HerdChek Swine Salmonella, IDEXX), following the manufacturer's instructions. Optical densities (OD) were determined by photospectrometry with a $650 \mathrm{~nm}$ filter. The outcome was expressed as a 'sample-to-positive' ratio:

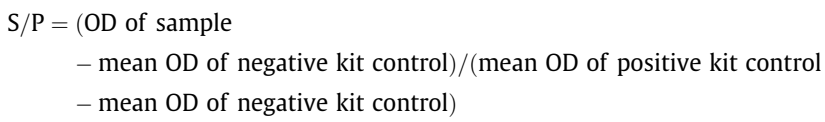

Samples with an S/P ratio $\geqslant 0.25$ (or OD\% $\geqslant 10$ ) were considered positive.

Statistical analysis

The number of positive faecal samples collected after challenge were compared between the groups using generalized estimating equations (GEE) (PROC GENMOD and lsmeans; SAS version 9.2). A logit link function, a binomial distribution and an autoregressive first order correlation matrix was assumed with repeated measures. A one-way ANOVA test was used to assess differences in the number of Salmonella spp. $\left(\log _{10}\right.$ normalized data) quantified in the faeces on Day 3, 7 and 24 .

The $\mathrm{S} / \mathrm{P}$ ratios obtained by the ELISA were analysed by repeated measures ANOVA using (PROC MIXED and lsmeans; SAS). Both pig and pen were considered random effects. An autoregressive first order correlation structure of was used for the within-subject correlation. In all models the Bonferroni correction was used to account for the use of multiple comparisons.

The transmission of Salmonella Typhimurium in each group was estimated on the basis of the stochastic 'susceptible-infectious' (SI) infection model using an 'adjusted' reproduction ratio ' $R_{a}$ '. This ratio expresses the mean number of secondary infections caused by one typically infectious animal in a fully susceptible population during a defined time period (3-14 weeks of age in this study) (Meyns et al. 2004). An Ra value of, for example, 1.76 implies that an infected pig from a group infects, on average, 1.76 pen mates during the observed period. These $R_{a}$ values were calculated via maximum likelihood estimation using each of the following definitions of infection. At least one positive sample was necessary to define an animal as Salmonella-positive based on: (1) individual faeces; (2) ileum and/or ileal content and/or caecum and/or caecal content; (3) ileocaecal lymph nodes and/or tonsils; (4) all tissue and/or all faecal samples.

Different definitions were used to assess the most suitable matrix for this estimation. For each of these four possible definitions the number of contact-infections was thus determined as variable ' $X_{i}^{\prime}$ '. The following equation was used for this estimation:

$R_{a, m l s}=\max _{R_{a}} \prod_{i=1}^{m} F\left(X_{i}, R_{a} \mid N, S_{0}, I_{0}\right)$

in which $F\left(X_{i}, R_{a} \mid N, S_{0}, I_{0}\right)$ is the likelihood function for the observed $X_{i}$-value, if $N$ (total number of piglets), $S_{0}$ (number of susceptible piglets), $I_{0}$ (number of infectious piglets) and $m$ (number of experiments) are given (Meyns et al., 2004).

\section{Results}

\section{Bacteriological examination}

All faecal samples taken prior to challenge were negative for Salmonella spp. No Salmonella spp. were isolated from the negative control group at any timepoint, supporting the conclusion that all other positive isolates were from infection with the introduced challenge strain. From challenge until euthanasia, the number of excreting pigs in group $C(58 \%)$ was significantly higher than in group A $(23 \%, P=0.01)$ and $B(15 \%, P=0.0001)$. Likewise, the number of shedding pigs in the positive control group (41\%) was significantly higher than in group B $(P=0.03)$, while no significant differences were observed between group $C$ and the positive control group (Fig. 1). These results were consistent with the Salmonella bacterial counts on Day 3,7 , and 24 . $\log _{10}$-values (CFU/g faeces) were $2.5,1.1$, and 0.7 for group A, 1.0, 0.3, and 1.1 for group $B, 3.6,2.3$, and 1.6 for group $C$ and 2.1, 1.2, and 1.3 for the positive control group, with only significant differences at Day 3 and 7 when group $C$ was compared with group $A(P=0.0066)$ and $B$ $(P=0.0002)$.

Of all organ samples, $18 \%, 31 \%, 64 \%$ and $41 \%$ were found to be positive for Salmonella in groups A, B, C and the positive control group, respectively (Table 3 ). Group $C$ had significantly more infected tissue samples than all other groups $(P<0.01)$. In group $B$, $31 \%$ of all organ samples contained the vaccine strain, with the proportion of vaccine-positive tonsils being higher than all other tissues $(P<0.01)$ (Fig. 2$)$.

The adjusted reproduction ratios $R_{a}$ for the different infection definitions are shown in Table 4. Overall $R_{a}$ values were lower in group $\mathrm{B}\left(R_{a}=2.6[1.21 ; 9.45]\right)$ and $\mathrm{A}\left(R_{a}=1.76[1.02 ; 9.01]\right)$ than group $C$ and the positive control group (both $R_{a}=+\infty[1.88 ;+\infty]$ ).

\section{Serological examination}

All pigs were seronegative before the start of the study. The evolution of Salmonella-specific antibody titres is illustrated for all groups in Fig. 3. During the entire experiment, titres in the negative control group remained very low ( $\mathrm{S} / \mathrm{P}$ ratios below 0.015$)$. In group $\mathrm{B}$, an increasing mean Salmonella-specific antibody response was observed from Day -19 until Day -1 (day of challenge) and also subsequently until the end of the experiment. In groups $\mathrm{A}$ and $\mathrm{C}$ and the positive control group, Salmonella-specific antibodies increased from 2 weeks after challenge; no significant differences 


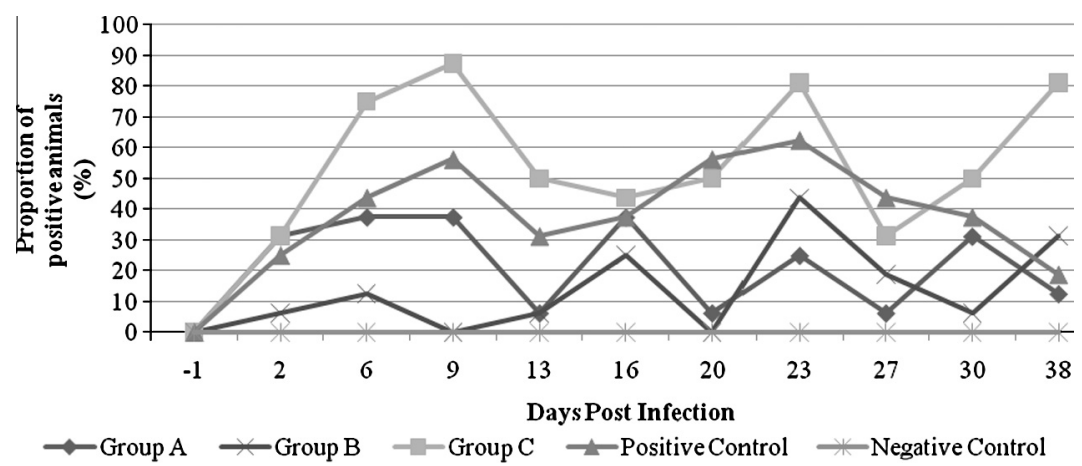

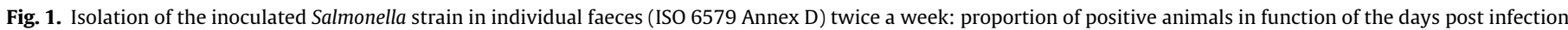

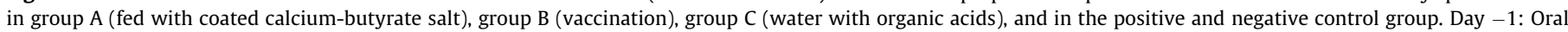


necropsy.

Table 3

Number of tissue and content samples positive for the challenge strain, Salmonella Typhimurium 112910a, in the four groups.

\begin{tabular}{|c|c|c|c|c|c|c|c|}
\hline \multirow[t]{2}{*}{ Group } & \multicolumn{6}{|c|}{ Different autopsy samples } & \multirow[t]{2}{*}{ All autopsy samples } \\
\hline & Ileum & Ileal content & Caecum & Caecal content & Ileocaecal lnn & Tonsils & \\
\hline $\mathrm{A}(n=16)$ & $4 / 16(25 \%)$ & $2 / 16(13 \%)$ & $2 / 16(13 \%)$ & $3 / 16(19 \%)$ & $3 / 16(19 \%)$ & $3 / 16(19 \%)$ & $17 / 96(18 \%)$ \\
\hline $\mathrm{B}(n=16)$ & $7 / 16(44 \%)$ & $4 / 16(25 \%)$ & $3 / 16(19 \%)$ & $6 / 16(38 \%)$ & $7 / 16(44 \%)$ & $3 / 16(19 \%)$ & $30 / 96(31 \%)$ \\
\hline$C(n=16)$ & $9 / 16(56 \%)$ & $5 / 16(31 \%)$ & $10 / 16(63 \%)$ & $13 / 16(81 \%)$ & $10 / 16(63 \%)$ & $14 / 16(88 \%)$ & $61 / 96^{a}(64 \%)$ \\
\hline $\mathrm{D}(n=16)$ & $9 / 16(56 \%)$ & $7 / 16(44 \%)$ & $6 / 16(38 \%)$ & $8 / 16(1 \%)$ & $6 / 16(38 \%)$ & $3 / 16(19 \%)$ & $39 / 96(41 \%)$ \\
\hline All groups $(n=64)$ & $29 / 64(45 \%)$ & $18 / 64(28 \%)$ & $21 / 64(33 \%)$ & $30 / 64(47 \%)$ & $26 / 64(41 \%)$ & $23 / 64(36 \%)$ & $147 / 384(38 \%)$ \\
\hline
\end{tabular}

A, feed with coated calcium-butyrate salt; B, vaccination; C, water with organic acids; D, positive control.

a Significant difference between group $C$ and the other groups $(P<0.03)$.

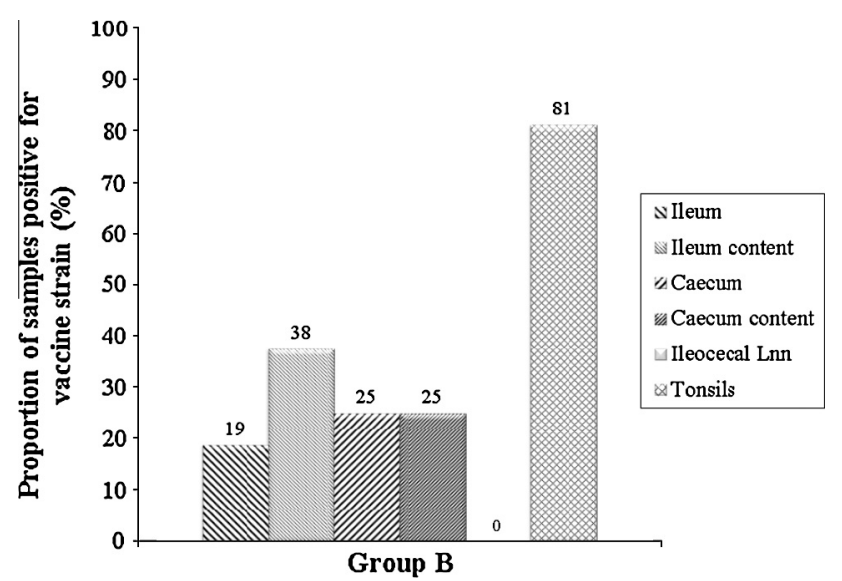

Fig. 2. Isolation of the Salmonella vaccine strain in different tissue samples (ISO 6579 Annex D + IDT Salmonella Diagnostic Kit): proportion (\%) of vaccine-positive samples from ileum/ileal content/caecum/caecal content/ileocaecal lymph nodes/ tonsils of group B (vaccination).

in titre were detected between these groups. The mean antibody titre of group B was significantly higher than all other groups.

\section{Discussion}

Current control measures are not sufficient to prevent the impact of pig-related Salmonella on public health. The present study investigated three intervention strategies to reduce the transmission of Salmonella Typhimurium in pigs. Supplementation of feed with coated calcium-butyrate and oral vaccination with an attenuated strain both limited Salmonella Typhimurium transmission; however, water acidified with various organic acids was shown in this study to be non-effective.

Using the present 'transmission' design, where treatment was given prior to challenge (treated seeders were brought together with treated contact pigs), an adjusted transmission ratio $R_{a}$ was calculated which quantified the effects of the treatments on both infectiveness and susceptibility. This is an important contrast to efficacy studies in which it is susceptibility that is principally tested, and not the combined effect (Springer et al., 2001; Roesler et al., 2004; Tanaka et al., 2010). A similar approach has been used in previous transmission experiments with other pathogens (Laevens et al., 1998; Dewulf et al., 2001; Velthuis et al., 2003; Heres et al., 2004; Meyns et al., 2004).

When observing the obtained transmission ratios, higher $R_{a}$ values were found in the group treated with acidified water (C) and in the untreated control group (D), independently of the definition of infection. This suggests a lower transmission of Salmonella in the treated groups A and B when compared to groups C and D. Yet, the $R_{a}$ value in both group A and B - based on the detection of Salmonella in faeces - was $>1$, indicating that there was still spread of the infection during the study period.

In the present trial, a coated calcium-butyrate supplement was chosen as one strategy, since this has been shown to be beneficial in previous experiments (Boyen et al., 2008b; Guilloteau et al., 2010), though not with the current transmission design. In the digestive tract, butyrate can accelerate the renewal of necrotic areas, down-regulate Salmonella virulence, suppress intestinal inflammation and diminish pathogen invasion (Hamer et al., 2008). To reach the colonization sites of Salmonella spp. (ileum, caecum and colon) in their active form, however, supplemented short-chain fatty acids need protection or 'coating' from the intestinal environment (Van Immerseel et al., 2005; Boyen et al., 2008b) because they are generally quickly metabolized and then absorbed by gastro-intestinal epithelial cells (Louis et al., 2007). The results 
Table 4

The adjusted reproduction ratio $R_{a}$ for the three intervention groups $\mathrm{A}, \mathrm{B}, \mathrm{C}$ and the positive control group D.

\begin{tabular}{|c|c|c|c|c|}
\hline Group & All individual faeces & Ileum/content/caecum/content & Ileocaecal $\operatorname{lnn} /$ tonsils & All organs/all faeces \\
\hline $\mathrm{A}(n=16)$ & $1.62[0.85 ; 8.43]$ & $0.77[0.35 ; 3.80]$ & $0.32[0.12 ; 2.94]$ & $1.76[1.02 ; 9.01]$ \\
\hline $\mathrm{B}(n=16)$ & $1.16[0.56 ; 3.95]$ & $1.03[0.56 ; 3.95]$ & $1.19[0.70 ; 7.18]$ & $2.61[1.21 ; 9.45]$ \\
\hline$C(n=16)$ & $3.53[1.88 ; 11.70]$ & $2.52[1.67 ; 24.87]$ & $3.53[1.88 ; 11.65]$ & $+\infty[1.88 ;+\infty]$ \\
\hline $\mathrm{D}(n=16)$ & $3.53[1.88 ; 11.70]$ & $1.91[1.22 ; 24.78]$ & $0.89[0.47 ; 4.23]$ & $+\infty[1.88 ;+\infty]$ \\
\hline
\end{tabular}

A, feed with coated calcium-butyrate salt; B, vaccination; C, water with organic acids; D, positive control; lnn, lymph nodes.

A pig was considered infected if at least one sample was positive during the transmission period.

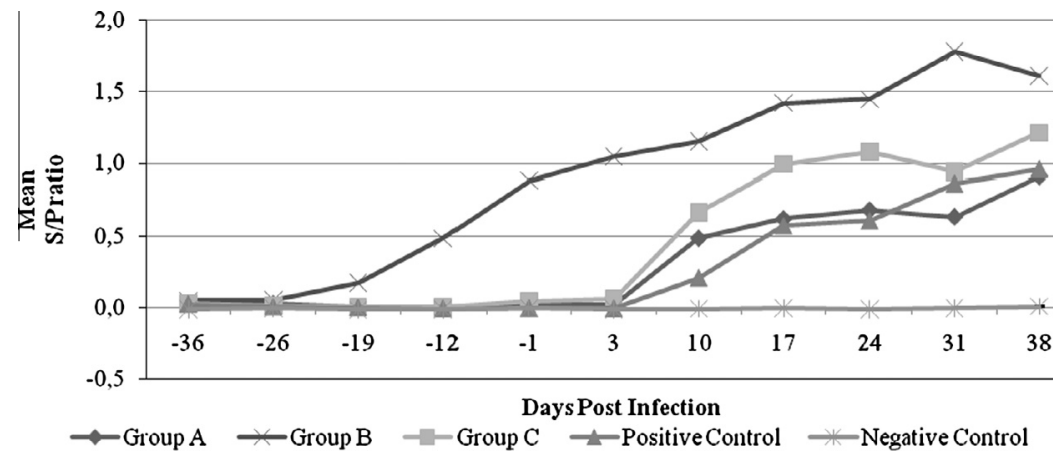

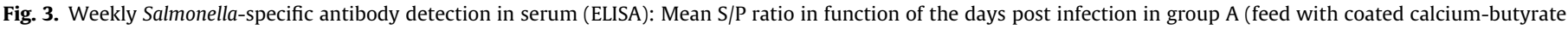

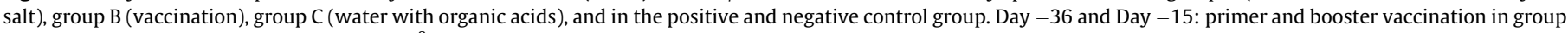

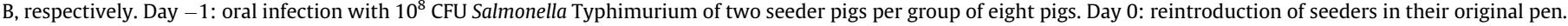
Day 38: euthanasia and autopsy.

of our study showed a tendency towards reduced Salmonella transmission in this group, in comparison with the acidified water group and the positive control group. Therefore, we conclude that coated calcium-butyrate may be helpful in the reduction of Salmonella infections in pigs.

In contrast, the addition of a mixture of formic, acetic, propionic, and lactic acid (Agrocid Super, CidLines) to the drinking water did not reduce the transmission rate of Salmonella Typhimurium in comparison with the positive control group. A possible explanation is that this acid shock induced a stress response system enabling Salmonella Typhimurium to survive in an extreme low acid environment (an acid tolerance response or 'ATR'; Foster and Spector, 1995; Suk Baik et al., 1996). Previous reports on the use of organic acids via drinking water have produced inconsistent results. Van der Wolf et al. (2001) observed a reduction in Salmonella when a $0.2 \% \mathrm{v} / \mathrm{v}$ organic acid mixture was administered during the entire finishing period. In contrast, no reductions were observed with the same concentration applied for a shorter time (2 weeks pre-slaughter) (De Busser et al., 2009), or using a lower concentration administered to weaners $(0.02 \% \mathrm{v} / \mathrm{v}$ in Letellier et al. (2000)). However, the comparison of these study results is hindered not only by the different duration of application or concentration, but also by the fact that different organic acid mixtures were used in all these studies.

The vaccine used in this study (Salmoporc, IDT) has been shown to reduce both faecal shedding and colonization of the intestinal tract of piglets (Springer et al., 2001). In the present transmission study, this vaccination resulted in the lowest number of shedding pigs and the lowest $R_{a}$ (faecal results). However, vaccination also increased the Salmonella-specific antibodies and resulted in a proportion of tissue samples colonized by Salmonella that was comparable to that in the positive control group ( $31 \%$ vs. $41 \%$, respectively).

Although the vaccine and wild type strains can be distinguished using the Salmonella Diagnostic Kit provided by the manufacturer of the vaccine, the commercial LPS-ELISA cannot differentiate between vaccination- and infection-induced antibodies in serum or meat juice. Vaccination may thus hamper the use of serology for
Salmonella monitoring programmes. Programmes that are based on bacteriology, new diagnostic tests that do not detect vaccine-induced antibodies (Selke et al., 2007), or new vaccines that are not detected by current ELISA methods (Leyman et al., 2011) are necessary if vaccination is to become a routine part of Salmonella control.

\section{Conclusions}

Both feed supplementation with coated calcium-butyrate and, particularly, vaccination with an attenuated vaccine, decreased Salmonella Typhimurium transmission in pigs. Further studies are needed to assess the practical issues related to the implementation of these promising interventions. For example, more data are needed to determine the best age groups and treatment regimens for the coated calcium-butyrate and to learn how to overcome the problem of Salmonella-specific antibodies in vaccinated pigs. Alternative bacteriology-based monitoring programmes, diagnostic tests that do not detect vaccine-induced antibodies or new vaccines that are not detected by current antibody detection methods are required.

\section{Conflict of interest statement}

None of the authors of this paper has a financial or personal relationship with other people or organisations that could inappropriately influence or bias the content of the paper.

\section{Acknowledgements}

We thank the Federal Public Service of Health, Food Chain Safety and Environment for the funding of this project (Contract RT 09/5 SalmoSu). The sampling assistance of Willem Van Campe and the technicians of the experimental centre is gratefully appreciated. We also thank Heidi Vander Veken, Andy Lucchina and Flor- 
ence Crombe for their help in processing the samples at the necropsy, and Wannes Vanderhaeghen and Leon Oosterik for their critical review.

\section{References}

Baptista, F.M., Dahl, J., Nielsen, L.R., 2010. Factors influencing Salmonella carcass prevalence in Danish pig abattoirs. Preventive Veterinary Medicine 95, 231238.

Boyen, F., Pasmans, F., Van Immerseel, F., Morgan, E., Botteldoorn, N., Heyndrickx, M., Volf, J., Favoreel, H., Hernalsteen, J., Ducatelle, R., Haesebrouck, F., 2008a. A limited role for SsrA/B in persistent Salmonella Typhimurium infections in pigs. Veterinary Microbiology 128, 364-373.

Boyen, F., Haesebrouck, F., Vanparys, A., Volf, J., Mahu, M., Van Immerseel, F., Rychlik, I., Dewulf, J., Ducatelle, R., Pasmans, F., 2008b. Coated fatty acids alter virulence properties of Salmonella Typhimurium and decrease intestinal colonization of pigs. Veterinary Microbiology 132, 319-327.

Canibe, N., Højberg, O., Hojsgaard, S., Jensen, B.B., 2005. Feed physical form and formic acid addition to the feed affect the gastrointestinal ecology and growth performance of growing pigs. Journal of Animal Science 83, 1287-1302.

CODA-CERVA-VAR, 2010. Salmonella Serotypes Analysed at the CODA-CERVA in 2010 - Evolution among Poultry, Cattle and Pig Isolates from 1999 to 2010 with Results of Antimicrobial Resistance Testing. Salmonella Rapport 2010, pp. 5-13.

Creus, E., Perez, J.F., Peralta, B., Baucells, F., Mateu, E., 2007. Effect of acidified feed on the prevalence of Salmonella in market-age pigs. Zoonoses and Public Health 54, 314-319.

Davies, R.H., Dalziel, R., Gibbens, J.C., Wilesmith, J.W., Ryan, J.M., Evans, S.J., Byrne, C., Paiba, G.A., Pascoe, S.J., Teale, C.J., 2004. National survey for Salmonella in pigs, cattle and sheep at slaughter in Great Britain (1999-2000). Journal of Applied Microbiology 96, 750-760.

De Busser, E.V., Dewulf, J., Nollet, N., Houf, K., Schwarzer, K., De Sadeleer, L., De Zutter, L., Maes, D., 2009. Effect of organic acids in drinking water during the last 2 weeks prior to slaughter on Salmonella shedding by slaughter pigs and contamination of carcasses. Zoonoses and Public Health 56, 129-136.

Denagamage, T.N., O'Connor, A.M., Sargeant, J.M., Rajic, A., McKean, J., 2007. Efficacy of vaccination to reduce Salmonella prevalence in live and slaughtered swine: A systematic review of literature from 1979 to 2007. Foodborne Pathogens and Disease 4, 539-549.

Dewulf, J., Laevens, H., Koenen, F., Mintiens, K., de Kruif, A., 2001. An E2-subunit marker vaccine does not prevent horizontal or vertical transmission of classical swine fever virus. Vaccine 20, 86-91.

Eddicks, M., Palzer, A., Hormansdorfer, S., Ritzmann, M., Heinritzi, K., 2009. Examination of the compatibility of a Salmonella Typhimurium-live vaccine Salmoporc for three day old suckling piglets. Deutsche Tierärztliche Wochenschrift 116, 249-254.

EFSA, 2008. Report of the task force on zoonoses data collection on the analysis of the baseline survey on the prevalence of Salmonella in holdings with breeding pigs in the EU, 2006-2007. Part A: Salmonella prevalence estimates. EFSA Journal 135, 1-111.

EFSA, 2011. The European Union summary report on trends and sources of zoonoses, zoonotic agents and food-borne outbreaks in 2009. EFSA Journal 9, 2090.

EFSA, 2012. The European union summary report on trends and sources of zoonoses, zoonotic agents and food-borne outbreaks in 2010. EFSA Journal 10, 2597.

Farzan, A., Friendship, R.M., Dewey, C.E., Warriner, K., Poppe, C., Klotins, K., 2006. Prevalence of Salmonella spp. on Canadian pig farms using liquid or dry-feeding. Preventive Veterinary Medicine 73, 241-254.

Farzan, A., Friendship, R.M., 2010. A clinical field trial to evaluate the efficacy of vaccination in controlling Salmonella infection and the association of Salmonella-shedding and weight gain in pigs. The Canadian Journal of Veterinary Research 74, 258-263.

Foster, J.W., Spector, M., 1995. How Salmonella survives against the odds. Annual Review of Microbiology 49, 145-174.

Guilloteau, P., Martin, L., Eeckhaut, V., Ducatelle, R., Zabielski, R., Van Immerseel, F., 2010. From the gut to the peripheral tissues: The multiple effects of butyrate. Nutrition Research Reviews 23, 366-384.

Hamer, H.M., Jonkers, D., Venema, K., Vanhoutvin, S., Troost, F.J., Brummer, R.J., 2008. Review article: The role of butyrate on colonic function. Alimentary Pharmacology and Therapeutics 27, 104-119.

Hauser, E., Tietze, E., Helmuth, R., Junker, E., Blank, K., Prager, R., Rabsch, W., Appel, B., Fruth, A., Malorny, B., 2010. Pork contaminated with Salmonella enterica serovar 4,[5],12:i:-, an emerging health risk for humans. Applied and Environmental Microbiology 76, 4601-4610.

Heres, L., Urlings, H.A., Wagenaar, J.A., de Jong, M.C., 2004. Transmission of Salmonella between broiler chickens fed with fermented liquid feed. Epidemiology and Infection 132, 107-116.

Hotes, S., Traulsen, I., Krieter, J., 2011. Salmonella control measures with special focus on vaccination and logistic slaughter procedures. Transboundary and Emerging Diseases 58, 434-444.

Hur, J., Song, S.O., Lim, J.S., Chung, I.K., Lee, J.H., 2011. Efficacy of a novel virulence gene-deleted Salmonella Typhimurium vaccine for protection against Salmonella infections in growing piglets. Veterinary Immunology and Immunopathology 139, 250-256.

Hurd, H.S., McKean, J.D., Griffith, R.W., Wesley, I.V., Rostagno, M.H., 2002. Salmonella enterica infections in market swine with and without transport and holding. Applied and Environmental Microbiology 68, 2376-2381.

Laevens, H., Koenen, F., Deluyker, H., Berkvens, D., de Kruif, A., 1998. An experimental infection with classical swine fever virus in weaner pigs. Transmission of the virus, course of the disease, and antibody response. Veterinary Quarterly 20, 41-45.

Letellier, A., Messier, S., Lessard, L., Quessy, S., 2000. Assessment of various treatments to reduce carriage of Salmonella in swine. The Canadian Journal of Veterinary Research 64, 27-31.

Leyman, B., Boyen, F., Van Parys, A., Verbrugghe, E., Haesebrouck, F., Pasmans, F., 2011. Salmonella Typhimurium LPS mutations for use in vaccines allowing differentiation of infected and vaccinated pigs. Vaccine 29, 3679-3685.

Lo Fo Wong, D.M.A., Dahl, J., Stege, H., van der Wolf, P.J., Leontides, L., von Altrock, A., Thorberg, B.M., 2004. Herd-level risk factors for subclinical Salmonella infection in European finishing-pig herds. Preventive Veterinary Medicine 62 253-266.

Louis, P., Scott, K.P., Duncan, S.H., Flint, H.J., 2007. Understanding the effects of diet on bacterial metabolism in the large intestine. Journal of Applied Microbiology 102, 1197-1208.

Mannion, C., Leonard, F.C., Lynch, P.B., Egan, J., 2007. Efficacy of cleaning and disinfection on pig farms in Ireland. Veterinary Record 161, 371-375.

McLaren, I., Wales, A., Breslin, M., Davies, R., 2011. Evaluation of commonly-used farm disinfectants in wet and dry models of Salmonella farm contamination. Avian Pathology 40, 33-42.

Meyns, T., Maes, D., Dewulf, J., Vicca, J., Haesebrouck, F., de Kruif, A., 2004. Quantification of the spread of Mycoplasma hyopneumoniae in nursery pigs using transmission experiments. Preventive Veterinary Medicine 66, 265-275.

O'Connor, A.M., Denagamage, T., Sargeant, J.M., Rajic, A., McKean, J., 2008. Feeding management practices and feed characteristics associated with Salmonella prevalence in live and slaughtered market-weight finisher swine: A systematic review and summation of evidence from 1950 to 2005. Preventive Veterinary Medicine 87, 213-228.

Poljak, Z., Dewey, C.E., Friendship, R.M., Martin, S.W., Christensen, J., 2008 Multilevel analysis of risk factors for Salmonella shedding in Ontario finishing pigs. Epidemiology and Infection 136, 1388-1400.

Regulation (EC) 2160/2003 of the European Parliament and of the Council of 17, 2003. On the control of Salmonella and other specified food-borne zoonotic agents. Official Journal of the European Union L325, 1-15.

Roesler, U., Marg, H., Schroder, I., Mauer, S., Arnold, T., Lehmann, J., Truyen, U., Hensel, A., 2004. Oral vaccination of pigs with an invasive gyrA-cpxA-rpoB Salmonella Typhimurium mutant. Vaccine 23, 595-603.

Roesler, U., Heller, P., Waldmann, K.H., Truyen, U., Hensel, A., 2006. Immunization of sows in an integrated pig-breeding herd using a homologous inactivated Salmonella vaccine decreases the prevalence of Salmonella Typhimurium infection in the offspring. Journal of Veterinary Medicine Series B 53, 224-228.

Selke, M., Meens, J., Springer, S., Frank, R., Gerlach, G.F., 2007. Immunization of pigs to prevent disease in humans: Construction and protective efficacy of a Salmonella enterica serovar Typhimurium live negative-marker vaccine. Infection and Immunity 75, 2476-2483.

Sørensen, L.L., Alban, L., Nielsen, B., Dahl, J., 2004. The correlation between Salmonella serology and isolation of Salmonella in Danish pigs at slaughter. Veterinary Microbiology 101, 131-141.

Springer, S., Lindner, Th., Steinbach, G., Selbitz, H.-J., 2001. Investigation of the efficacy of a genetically-stabile live Salmonella Typhimurium vaccine for use in swine. Berliner und Münchener Tierarztliche Wochenschrift 114, 342-345.

Suk Baik, H., Bearson, S., Dunbar, S., Foster, J.W., 1996. The acid tolerance response of Salmonella Typhimurium provides protection against organic acids. Microbiology 142, 3195-3200.

Tanaka, T., Imai, Y., Kumagae, N., Sato, S., 2010. The effect of feeding lactic acid to Salmonella Typhimurium experimentally infected swine. Journal of Veterinary Medical Science 72, 827-831.

Taube, V.A., Neu, M.E., Hassan, Y., Verspohl, J., Beyerbach, M., Kamphues, J., 2009. Effects of dietary additives (potassium diformate/organic acids) as well as influences of grinding intensity (coarse/fine) of diets for weaned piglets experimentally infected with Salmonella Derby or Escherichia coli. Journal of Animal Physiology and Animal Nutrition 93, 350-358.

van der Wolf, P.J., van Schie, F.W., Albers, A.R.W., Engel, B., van der Heijden, H.M.J.F., Hunneman, W.A., Tielen, M.J.M., 2001. Administration of acidified drinking water to finishing pigs in order to prevent Salmonella infections. Veterinary Quarterly 23, 121-125.

Van Immerseel, F., Boyen, F., Gantois, I., Timbermont, L., Bohez, L., Pasmans, F., Haesebrouck, F., Ducatelle, R., 2005. Supplementation of coated butyric acid in the feed reduces colonization and shedding of Salmonella in poultry. Poultry Science 84, 1851-1856.

Velthuis, A., de Jong, M., Kamp, E., Stockhofe, N., Verheijden, J., 2003. Design and analysis of an Actinobacillus pleuropneumoniae transmission experiment Preventive Veterinary Medicine 60, 53-68.

Wales, A.D., McLaren, I.M., Bedford, S., Carrique-Mas, J.J., Cook, A.J., Davies, R.H., 2009. Longitudinal survey of the occurrence of Salmonella in pigs and the environment of nucleus breeder and multiplier pig herds in England. Veterinary Record 165, 648-657. 